\title{
Ein ärztekritischer Ratgeber
}

\section{Iris Ritzmann}

Prof. Dr. med. et lic. phil., Mitglied der Redaktion Medizingeschichte

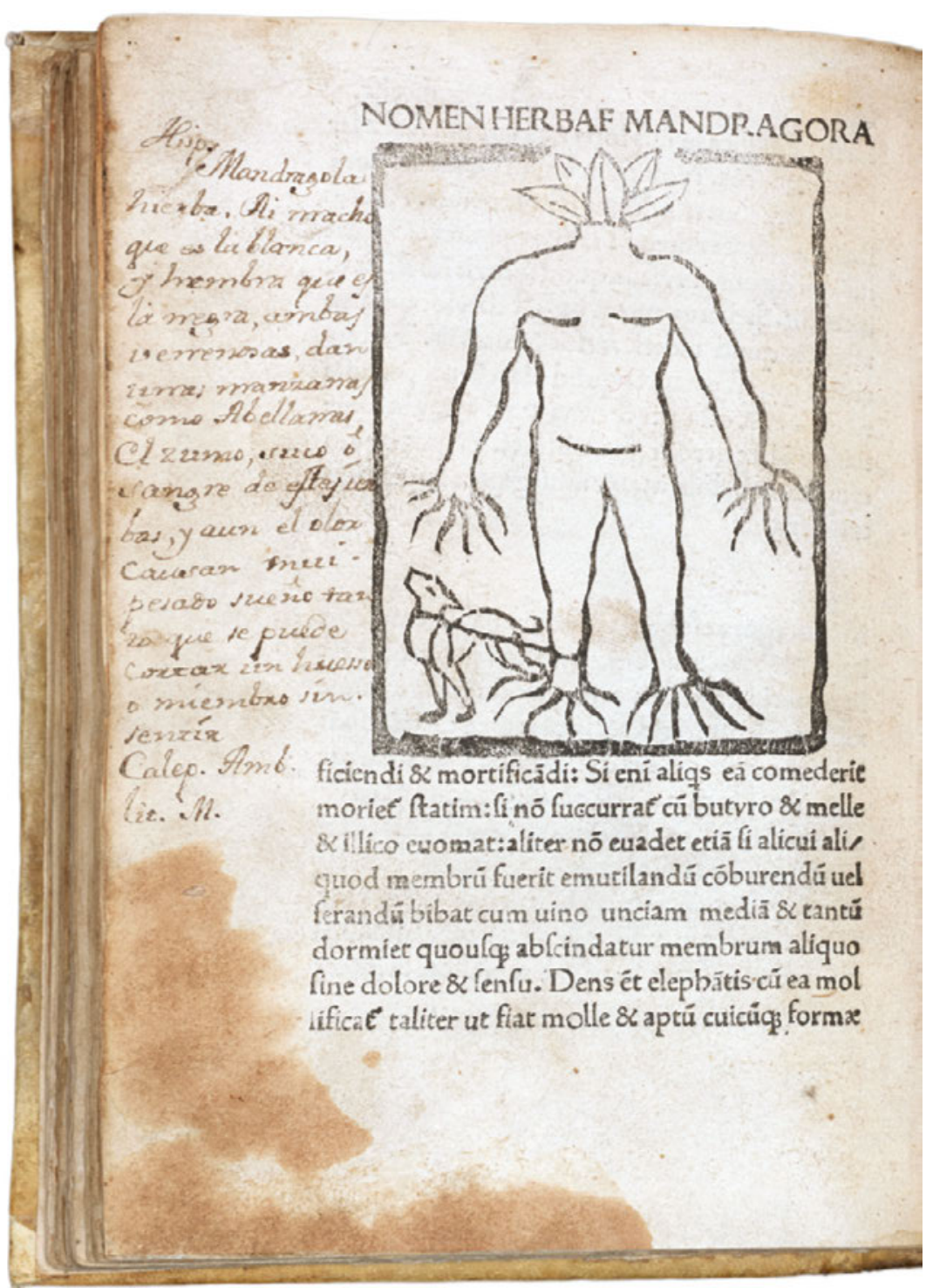

Apuleius Platonicus: Incipit Herbarium, Rom (ca. 1481), Nomen Herbae Mandragora mit spanischen Marginalien, Sammlung Dr. Franz Käppeli.
Kritik an der Ärzteschaft ist keineswegs ein Thema der Moderne. Bereits in der Spätantike beginnt Apuleius Platonicus seinen «Incipit Herbarius» mit der Aussage, Ärzte seien habgierig, ziehen die Behandlung aus Gewinnsucht in die Länge und seien gefährlicher als die Krankheiten selbst. Deshalb soll sein Kräuterbuch den Kranken die Selbstbehandlung ermöglichen. Über den Autor ist nicht mehr bekannt, als dass er den Namen des römischen Dichters und Philosophen Apuleius als Pseudonym verwendete.

Der Holzschnitt zeigt eine Alraune, auf Latein Mandragora. Da ihre Form als menschenähnlich wahrgenommen wurde, wies man ihr eine eigene machtvolle Persönlichkeit zu. Wer eine Alraune unbedacht aus dem Boden zog, konnte von ihr mit dem Tode bestraft werden. Daher rät der Herbarius, die Alraune an einen Hund festzubinden, der die Pflanze ausziehen und damit die Rache der Alraune auf sich lenken soll. Der Aufwand lohne sich, denn die Wurzel wirke in verschiedener Zubereitung hervorragend gegen Schmerzen, Ausschläge und vielerlei weitere Leiden.

Der Herbarius fand über mehrere mittelalterliche $\mathrm{Ab}$ schriften schlussendlich den Weg zum gedruckten Buch. Niemand Geringerer als der erste Buchdrucker Italiens und zugleich Leibarzt des Papstes, Johannes Philippus de Lignamine, druckte das Werk 1481 in Rom. Es handelt sich um eine Inkunabel, auf Deutsch Wiegendruck, ein Druckerzeugnis aus der Zeit bis 1500, als der Buchdruck noch in der Wiege lag. Wie bei den meisten Inkunabeln beginnt auch der Titel dieses Buchs mit «Incipit», was lediglich "es beginnt» bedeutet.

Der spätantike Gesundheitsratgeber unterscheidet sich von damaligen Kräuterbüchern durch die zahlreichen Holzschnitte und die Anordnung der Arzneipflanzen, die nicht dem Alphabet, sondern dem Ort des Leidens von Kopf bis Fuss folgt. Im hinteren Teil des Herbarius werden jene Kräuter beschrieben, die nicht einzelne Körperteile oder Organe heilen, sondern auf den ganzen Körper wirken. Hier finden sich die magischen Allheilmittel, die sogenannten Panazeen. Inhaltlich jedoch entsprechen die Ratschläge des Apuleius Platonicus weitestgehend den üblichen ärztlichen Anweisungen, auch was das Ausgrabungsritual der Alraune betrifft. War der Autor vielleicht selber Arzt und die laute Ärzteschelte nicht mehr als ein Verkaufstrick?
Bildnachweis

iris.ritzmann[at]saez.ch 